\title{
RELATIONSHIP OF VICARIOUS TRAUMATIZATION WITH FAMILY RELATIONS AND COPING STRATEGIES AMONG HEALTHCARE PROFESSIONALS
}

\author{
Nazia Mustafa, Fahad Haleem, Najm Us Saqib Khan*, Tahir Sardar**, Muhammad Naveed Akhtar**, Javaria Mumtaz*** \\ General Headquarter, Rawalpindi Pakistan, *Naval Headquarters, Islamabad Pakistan, **Army Medical College/National University of \\ Medical Sciences (NUMS) Rawalpindi Pakistan, ${ }^{* * * T H Q ~ H o s p i t a l, ~ A r i f w a l a ~ P a k i s t a n ~}$
}

\begin{abstract}
Objective: To study the relationship of vicarious traumatization with family relations and coping strategies among Health care professionals along with to find out the frequency of vicarious traumatization.

Study Design: Cross sectional study.

Place and Duration of Study: Various hospitals in Rawalpindi and Islamabad, from Jan2018 to Jun 2018.

Methodology: A sample of 170 healthcare professionals (doctors $=39$, psychiatrists $=27$, psychologists $=36$, nurses= 30 and others=38) $(\mathrm{men}=67$, women=103) were taken from various hospitals in Rawalpindi and Islamabad. Data was collected by using the secondary traumatic stress scale, the index of family relations and the brief COPE scale.

Results: Results revealed that all the instruments have good reliability and there was significant positive correlation ( $\mathrm{r}=0.71)$ between various aspects of VT (intrusion, avoidance and arousal) and poor family relations. Further analysis reflected that Emotion focused coping was positively correlated $(\mathrm{r}=0.22)$ with poor family relations whereas problem focused coping was negatively correlated $(\mathrm{r}=-0.39)$ with poor family relations.

Conclusion: So it is concluded that vicarious traumatization must be addressed and identified in health setting and coping skills training must be part of healthcare professionals' education programs.
\end{abstract}

Keywords: Coping strategies, Family relations, Healthcare professionals, Vicarious traumatization.

This is an Open Access article distributed under the terms of the Creative Commons Attribution License (http://creativecommons.org/licenses/by/4.0), which permits unrestricted use, distribution, and reproduction in any medium, provided the original work is properly cited.

\section{INTRODUCTION}

Pakistan has faced many unanticipated disasters in past few years. Which left massive legacy of human suffering by affecting the people physically and psychologically. These events also cause an incredible amount of fear and insecurity among the people who were not directly affected by these disasters ${ }^{1}$. In such stressful situations, Healthcare Professionals are the individuals who assist victims. Their work is extremely challenging which make the mvulnerable for vicarious traumatization ${ }^{2}$.

Literature revealed that about 10 percent of these personnel get affected and 30\% reported post-traumatic symptoms. A case study of therapist working in disaster situations in Pakistan showed that he became a victim of psychological suffering himself while working with sufferers ${ }^{3}$.

Correspondence: Dr Nazia Mustafa, Flat \# C, Block E-15, General Javed Shaheed Colony, Convoy Road, Rawalpindi Pakistan Received: 22 Oct 2020; revised received: 23 Nov 2020; accepted: 17 Dec 2020
A research on 236 social workers after 20 months of terrorist attack on World Trade Centre was conducted and their findings indicate the presence of secondary trauma among them ${ }^{4}$. Similar results were found for 76 Humanitarian aid workers in India and $8 \%$ of them met the criteria of PTSD 5 . Many other studies have been carried out with therapist, counselors, social workers and nurses with similar findings ${ }^{6}$.

Vicarious trauma can also negatively affect work, relationships and the overall functioning of these professionals 7 . One hundred and twenty seven wives of Israeli individuals who involved in combat were studied and results showed conflict and rigidity in their family functioning as compared to control group ${ }^{8}$. A longitudinal study showed that post disasters symptomatology has negative relation with family life. These professionals employed a number of positive and negative coping strategies to deal with stress associated with their care-giving role. Jacobson studied social workers, psychologists, marriage/family 
counselors and other mental health professionals who experienced secondary stress. He found that they tend to use both adaptive (problem focused) and maladaptive coping (emotional focused coping) skills to deal with their stress ${ }^{9}$.

Further studies showed that the problemfocused coping strategies are correlated with greater well-being whereas emotion-based coping is inversely related to it. Researchers explored coping strategies retrospectively reported by professionals who work with maltreated children and their families. According to them, workers frequently used problem-focused coping strategies and sought social support. In another study, it is pointed out that sexual assault counselors experience greater emotional exhaustion and use more avoidance coping strategies ${ }^{10}$.

Tough study of vicarious traumatization is gaining attention now days, but findings aremeager and inconsistent. There are many researchers conducted in various parts of world showing the high prevalence of vicarious traumatization among all those who are working with traumatized individuals. Simultaneously, there is literature which does not support this hypothesis that trauma affects others. This situation creates the need to see the presence of vicarious traumatization in our healthcare professionals and to develop the strategies to help them. Because if healthcare professional becomes negatively affected through vicarious traumatization, the treatment of primary victims becomes compromised. In Pakistan, this area is neglected and there is very limited research on this topic especially after earthquake 2005, flood 2010 and APS attack 2014. Therefore, the present study is designed with objective to determine the frequency of vicarious traumatization (Arousal, Intrusion and Avoidance) among healthcare professional and its relationship with family functioning and coping strategies who are working with traumatized individuals in Pakistan.

\section{METHODOLOGY}

A sample of 170 (Men=67 Women=103). Healthcare professional who were working with traumatized individuals (doctors $=39$, psychiatrists $=27$, clinical psychologists $/$ psychologists $=$ 36 , nurses $=30$ and others $=30$ ) was collected from various private/public sector hospitals in Rawalpindi and Islamabad through purposive sampling technique.

After obtaining their consent they were asked to fill the three questionnaires along with demographic sheet; the Secondary Traumatic Stress Scale (STSS), which designed to specifically measure secondary trauma symptoms. It is a 17-item Likert-type response format ranging from 1 (never) to 5 (very often) instrument with Its reliability is 0.94 for full scale and the Intrusion, Avoidance, and Arousal subscales had alphas of $0.83,0.89$, and 0.85 , respectively ${ }^{11}$. The Index of Family Relations (IFR) designed to measure the degree, severity, or magnitude of the problem that family members perceive in their relationship and its reliability alpha is $0.95^{12}$. The IFR comprises of 25 items ranging from 1 (never) to 5 (very often). Reverse scoring has been assigned to following items (positively worded items); 1,2,4,5, $8,14,17,18,20,21$ and 23 . The negatively worded items scored in normal way. High scores on it indicated poor family relations. The Brief COPE scale is a self-report questionnaire used to assess a number of different coping behaviors and thoughts a person may have in response to a specific situation. The scale comprises of 28 items and 14 subscales, comprised of two items each ${ }^{26}$. The Brief COPE full scale reliability 0.81 was divided into problem-based and emotion-based coping 0.79 and 0.75 , respectively ${ }^{19}$. The data was entered on SPSS-20 and analyzed. Descriptive Statistics were carried out to describe the mean, SD, frequencies and reliability coefficients. Person Correlation was used to see the relationship between different variables.

\section{RESULTS}

Results revealed that age of participants was between range of 19 to 51 years $(M=31.74$, $\mathrm{SD}=6.74)$. Further, secondary traumatic stress scale (STSS) ( $\mathrm{r}=0.92)$, Index of Family Relations 
(IFR) $(\mathrm{r}=0.90)$ and Brief-COPE $(\mathrm{r}=0.74$ and $\mathrm{r}=0.49)$ were reliable.

Table-III shows the correlation coefficients of various aspects of vicarious traumatization and two types of coping with family relations. Results revealed that intrusion, avoidance and arousal components of vicarious traumatization were significantly correlated with family relations. Whereas Emotion Focused coping positively correlated with family relations and problem focused coping strategies were negatively correlated with family relations.

Table-I: Descriptive statistics of variables $(\mathrm{n}=170)$.

\begin{tabular}{l|c}
\hline Variables & Mean \pm SD \\
\hline Vicarious traumatization & $42.62 \pm 11.77$ \\
\hline Intrusion & $11.82 \pm 3.28$ \\
\hline Avoidance & $17.84 \pm 5.34$ \\
\hline Arousal & $12.96 \pm 4.21$ \\
\hline Family relations & $64.56 \pm 18.64$ \\
\hline Coping Strategies & $54.56 \pm 7.22$ \\
\hline Emotion focused coping & $16.59 \pm 2.63$ \\
\hline Problem focused coping
\end{tabular}

Table-II: Frequencies and percentages of various aspect of vicarious traumatization $(n=170)$.

\begin{tabular}{l|c}
\hline Symptoms & $\mathbf{n ~ ( \% )}$ \\
\hline Intrusion & $113(66.47)$ \\
\hline Avoidance & $91(53.53)$ \\
\hline Arousal & $108(63.53)$ \\
\hline Vicarious traumatization & $102(60)$ \\
\hline
\end{tabular}

Table-III: Correlation coefficients of various aspects of vicarious traumatization andtypes of coping strategies with family relations $(\mathbf{n}=\mathbf{1 7 0})$.

\begin{tabular}{l|c|c|c|c|c|c|c}
\hline Variables & 1 & 2 & 3 & 4 & 5 & 6 & 7 \\
\hline Intrusion & - & - & - & - & - & - & $0.57^{*}$ \\
\hline Avoidance & & - & - & - & - & - & $0.69^{*}$ \\
\hline Arousal & & & & - & - & - & $0.68^{*}$ \\
\hline VT & & & & & - & - & $0.71^{*}$ \\
\hline EF coping strategies & & & & & & - & $0.22^{*}$ \\
\hline PF coping strategies & & & & & & - & $-0.39^{*}$ \\
\hline Family Relations & & & & & & & - \\
\hline${ }^{*} p<0.01$ & \multicolumn{6}{|l}{}
\end{tabular}

\section{DISCUSSION}

Pakistan is the country which faced all types of disasters and Health care professionals are individuals who come as frontline worriers in such situations. They are mostly rescue person- nel, the military, trauma healthcare staff and certain sections of social services. These individuals come across to the extreme human suffering and observe the emotions of fear, helplessness and horror ondaily basis. This may lead to increase in likelihood of experiencing a change in their own psychological functioning 2 .

So present study was conducted to see the relationship of VT with family functioning and coping strategies among healthcare professionals. Psychometric properties of instruments were calculated and findings suggested satisfactory alpha coefficient all scales which were consistent with the previous findings ${ }^{11}$.

Correlation coefficients were taken among the variables and values are satisfactory which shows that healthcare professionals are under continues stress because of their professional hazards (vicarious traumatization) and strains in their personal lives because of negative impact of that stress. They employed a number of positive and negative coping strategies to deal with the stress associated with their care giving role ${ }^{13,14,15}$.

\section{CONCLUSION}

Trauma and disasters are unavoidable conditions in our society and healthcare professionals are those individuals who help the sufferers of these conditions. They themselves are venerable and develop the symptoms of vicarious traumatization. In present research the prevalence of vicarious traumatization is high among these professionals which negatively affect their family relations. So it is suggested that if these professionals use emotion focused coping, it will make their family relations poor whereas problem focused coping help them to reduce strain in their relations. The findings of present research emphasized that vicarious traumatization must be addressed and identified in health setting and coping skills training must be part of healthcare professionals' education programs.

\section{CONFLICT OF INTEREST}

This study has no conflict of interest to be declared by any author. 


\section{REFERENCES}

1. Branson DC. Vicarious trauma, themes in research, and terminology: A review of literature. Traumatol 2010; 25(1): 2-10.

2. Niaz U. The day the mountains moved: international perspectives on handling psycho-trauma. J Pak Psychiatr Soc 2007; 4(2): 01-05.

3. Bilal MS, Rana MH, Rahim S, Ali S. Psychological trauma in a relief worker - A ease report from earthquake-struck areas of north Pakistan. Prehospital Disast Med 2007; 22(5): 458-61.

4. Richard EA, Charles RF, Joseph AB. The compassion fatigue scale: its use with social workers following urban disaster. Sage Pub 2007; 18(3): 238-50.

5. Shah SA, Garland E, Katz C. Secondary traumatic stress prevalence in humanitarian aid workers in India. Traumatol 2007; 13(1): 59-70.

6. Albin WK. Effects of treating trauma survivors: Vicarious traumatization and style of coping. Dissert Abstract Inter 2000; 60(9): 4915.

7. Mc Farlane AC, Bookless C. The effect of PTSD on interpersonal relationships: Issues for emergency service-workers. Sex Rel Thera 2010; 16(3): 261-67.

8. Mark W, Mario M, Zahava S, Matisyohu W. Secondary traumatization among wives of posttraumatic combat veterans: A family typology. J Fam Psychol 1993; 7(1): 104-18.

9. Steinglass P, Gerrity E. Natural disasters and post-traumatic stress disorder short-term versus long-term recovery in two disaster-affected communities. J Appl Social Psychol 2006; 20(21): 1746-65.

10. Johnson $\mathrm{CN}$, Hunter M. Vicarious traumatization in counselors working in the New South Wales Sexual Assault Service: An exploratory study. Work \& Stress: Int J Work Health Org 1997; 11(4): 319-28.

11. Bride BE, Robinson MR, Yegidis B, Figly CR. The secondary traumatic stress scale. Res Social Work Pract 2003; 13(1): 1-16.

12. Khurshid M. Rehman G. Impact of peer relations on the selfesteem of juvenile delinquents. J Pak Psychiatr Soc 2006; 3(2): 78-82.

13. Chambers M, Connor SL. Exploring the emotional support needs and coping strategies of family carers. J Psychiatr Mental Health Nurs 2001; 8(2): 99-06.

14. Hastings RP, Kovshoff H, Brown T, Ward NJ, Espinosa FD, Remington B. Coping strategies in mothers and fathers of preschool and school-age children with autism. Autism 2005; 9(4): 377-91.

15. Hunter SV, Schofile MJ. How counselors cope with traumatized clients: Personal, professional and organizational strategies. Inter J Advanc Counsel 2006; 28(2): 121-38. 